\title{
Desempenho e digestibilidade dos nutrientes em cordeiros alimentados com dietas contendo silagem de resíduos de peixe ${ }^{1}$
}

\section{Sandra Mari Yamamoto ${ }^{2}$, Américo Garcia da Silva Sobrinho ${ }^{3}$, Rose Meire Vidotti ${ }^{4}$, Antonio Carlos Homem Junior ${ }^{5}$, Rafael Silvio Bonilha Pinheiro ${ }^{6}$, Carolina Buzzulini ${ }^{5}$}

\author{
1 Projeto financiado pela FAPESP. \\ 2 Pós-doutoranda do Programa de Pós-graduação em Zootecnia da Universidade Estadual de Maringá. Bolsista de Pós-doutorado Júnior \\ do CNPq. \\ ${ }^{3}$ Departamento de Zootecnia da Faculdade de Ciências Agrárias e Veterinárias, FCAV/Unesp, Jaboticabal, SP. \\ ${ }^{4}$ Instituto de Pesca, São José do Rio Preto, SP. \\ 5 Pós-graduação em Zootecnia da FCAV/Unesp. \\ ${ }^{6}$ Pós-graduação em Zootecnia da Faculdade de Medicina Veterinária e Zootecnia, FMVZ/Unesp, Botucatu, SP.
}

RESUMO - Foram utilizados 36 cordeiros 7/8 Ile de France 1/8 Ideal (18 machos e 18 fêmeas) com peso corporal inicial de 17,90 \pm 1,27 kg alimentados com as dietas: controle; SRPAD - com 8\% de silagem de resíduo do processamento de tilápia (Oreochromis niloticus); e SRPAM - com 8\% de silagem de resíduo do processamento de peixe-sapo (Lophius gastrophisus). As silagens de resíduos de peixes substituíram parcialmente o farelo de soja e, como volumoso, utilizou-se silagem de milho (40\%). Os cordeiros foram mantidos em baias individuais, com controle do alimento fornecido e das sobras e pesagem a cada 14 dias até atingirem $32 \mathrm{~kg}$, quando foram realizadas as medidas biométricas. Paralelamente, foram realizados ensaios de digestibilidade e de metabolismo utilizando-se 12 cordeiras 7/8 Ile de France 1/8 Ideal para determinação dos coeficientes de digestibilidade da MS, MO, PB, EE, FDN e CT e do balanço de nitrogênio das dietas experimentais. O consumo de MS e o ganho médio diário não foram influenciados pelas dietas e pelo sexo e apresentaram médias de 891,83 e 240,26 g/dia, respectivamente. Entretanto, a conversão alimentar dos cordeiros alimentados com as dietas com SRPAM foi pior $(4,04)$ em relação à daqueles alimentados com as dietas controle $(3,81)$ e com SRPAD $(3,47)$. Os cordeiros apresentaram maior comprimento corporal (60,09 cm) e altura do anterior $(56,11 \mathrm{~cm})$ em comparação às cordeiras (58,03 e 54,75 cm, respectivamente). Cordeiros alimentados com dietas contendo SRPAD tiveram maior ingestão de EE e melhor coeficiente de digestibilidade do EE (90,39\%), enquanto aqueles alimentados com a dieta controle apresentaram o menor coeficiente de digestibilidade da FDN (59,20\%) A substituição parcial do farelo de soja por silagem de resíduos de peixes mostrou-se como boa alternativa protéica na alimentação de cordeiros.

Palavras-chave: digestibilidade, ganho de peso, ovinos, resíduos de pescado

\section{Performance and digestibility of nutrients in lambs fed diets containing fish residue silage}

\begin{abstract}
Thirty six 7/8 Ile de France 1/8 Polwarth (18 males and 18 females) lambs averaging $17.90 \pm 1.27 \mathrm{~kg}$ of body weigh (BW) were randomly assigned to one of the following three diets: 1) control diet; 2) SRPAD - 8\% freshwater fish (Oreochromis niloticus) residue silage; or 3) SRPAM - 8\% sea fish (Lophius gastrophisus) residue silage. The fish residue silages partially replaced soybean meal in the diet; corn silage (40\% DM basis) was used as the sole forage source. Animals were feed-restricted and maintained in individual stalls; lambs were weighted every 14 days until they reached $32 \mathrm{~kg}$ of BW when biometrical measurements were taken. Twelve 7/8 Ile de France 1/8 Polwarth female lambs were used for determination of nutrient digestibility and nitrogen balance. Dry matter intake and average daily weight were not affected by diet and gender averaging 891.83 and 240.26 g/day, respectively. However, lambs that received SRPAM had greater feed conversion (4.04) than those fed the control diet (3.81) and SRPAD (3.47). Male lambs showed greater body length $(60.09 \mathrm{~cm})$ and forelimb height $(56.11 \mathrm{~cm})$ than the female counterparts. Intake and digestibility $(90.39 \%)$ of EE was highest in lambs fed SRPAD while NDF digestibility (59.20\%) was lowest in those fed the control diet. It can be concluded that fish residue silage can partially replace soybean meal in the diet.
\end{abstract}

Key Words: digestibility, fish residue, sheep, weight gain 


\section{Introdução}

Nos últimos anos, a participação sócio-econômica da carne ovina tem sido crescente na atividade pecuária do estado de São Paulo. Entretanto, a qualidade das carcaças comercializadas nem sempre atende às características desejadas pelo consumidor, que valoriza carcaças de animais jovens, abatidos com idade inferior a 150 dias e peso corporal entre 28 e $32 \mathrm{~kg}$. Sistemas de criação adequados, com utilização intensiva de pastagens e terminação de cordeiros em confinamento são necessários para alcançar esses objetivos.

A deficiência nutricional nas diferentes fases do processo produtivo é um dos obstáculos ao desenvolvimento da produção ovina no Brasil. Assim, são válidos todos os esforços de pesquisas na área de alimentação animal para elevação dos índices de produção e produtividade dos rebanhos. A terminação de cordeiros em confinamento tem apresentado balanço econômico desfavorável em relação aos custos de insumos, principalmente os concentrados protéicos. Nesse sentido, fontes protéicas alternativas, principalmente na forma de subprodutos ou resíduos, têm sido utilizadas como opção aos alimentos tradicionais.

A atividade pesqueira gera grande quantidade de resíduos nas formas de descarte da comercialização in natura e do processamento. Como exemplo, a quantidade diária de pescado não comercializado na região metropolitana de São Paulo (aproximadamente uma tonelada) é descartada pelo Serviço de Inspeção Federal do Ministério da Agricultura por não estar apta ao consumo humano. Estes subprodutos podem gerar problemas ambientais ao serem depositados nos lixões urbanos ou enterrados, prática muito comum em indústrias de pequeno porte (Vidotti et al., 2002).

A silagem de peixe é uma alternativa simples de aproveitamento desses subprodutos e de grande eficiência biológica e econômica (Windsor \& Barlow, 1984). Entretanto, apesar da grande disponibilidade de subprodutos de pescado no Brasil, há escassez de pesquisas visando seu aproveitamento na alimentação de ruminantes.

Maia Jr. et al. (2000) destacaram as vantagens da produção de silagem de peixe em relação à de farinha de peixe, como produção de acordo com a demanda, uso de mão-deobra não especializada e baixo investimento de capital. Esses autores ressaltaram a rapidez e simplicidade do processo de produção em condições tropicais, pelo qual é dispensável a refrigeração no armazenamento. A silagem, mesmo sem secagem, é estável; no processamento, exige baixo consumo de energia e as enzimas específicas melhoram sua aceitabilidade e digestibilidade do produto e ainda evitam sua deterioração (Oetterer, 1993).
Na alimentação de ruminantes, as principais fontes de proteína são a microbiana e a dietética que escapa da degradação ruminal. Essas fontes, quando digeridas no abomaso e no intestino delgado, atendem às exigências de aminoácidos dos ruminantes. Segundo Hall (1984), a silagem de peixe se assemelha à farinha de peixe no perfil de nutrientes, entretanto, possui maior degradabilidade ruminal da proteína por ser parcialmente hidrolisada em peptídeos na fermentação. O valor nutricional da silagem de peixe é atribuído à elevada digestibilidade da proteína e à composição de aminoácidos livres, principalmente lisina e triptofano. Durante o processamento da silagem, as proteínas são hidrolisadas em aminoácidos livres por enzimas presentes nos músculos dos peixes, tornando os aminoácidos mais disponíveis para biossíntese protéica ruminal.

O consumo alimentar é o primeiro parâmetro a ser considerado na formulação de dietas, além de ser a medida mais associada ao desempenho animal. Portanto, as características físicas e/ou químicas do alimento podem afetar positivamente ou negativamente a ingestão. Além disso, os coeficientes de digestibilidade dos nutrientes afetam diretamente o desempenho animal, pois permitem calcular as quantidades aparentemente absorvidas desses alimentos no trato gastrintestinal (Ítavo et al., 2002).

$\mathrm{O}$ balanço de $\mathrm{N}$ permite quantificar a retenção de nitrogênio no organismo por meio da diferença entre o nitrogênio consumido e o excretado nas fezes e na urina (Harris, 1970), constituindo importante indicador do ganho ou da perda de proteína em animais alimentados com diferentes dietas. O método, no entanto, apresenta algumas limitações, pois parte do nitrogênio excretado é de origem endógena.

Objetivou-se neste estudo avaliar o ganho de peso, o consumo de MS, a conversão alimentar, o tempo de confinamento e as medidas biométricas de cordeiros alimentados com dietas contendo silagens de resíduos de peixes e estudar a digestibilidade de nutrientes e o balanço de nitrogênio destas dietas.

\section{Material e Métodos}

Foram utilizados 36 cordeiros 7/8 Ile de France 1/8 Ideal (18 machos e 18 fêmeas) com peso corporal inicial de 17,90 $\pm 1,27$ kg. Os animais foram identificados com marcação numérica na região lombar e confinados em baias individuais com piso ripado suspenso, equipadas com comedouros e bebedouros.

Três dietas isoprotéicas e isoenergéticas foram formuladas de acordo com as exigências descritas pelo AFRC 
(1995) utilizando-se como volumoso silagem de milho na proporção de $40 \%$. Os concentrados utilizados continham como fonte protéica o farelo de soja ou $8 \%$ (na MS) de silagem de resíduos do processamento de tilápia (peixe de água doce), ou peixe-sapo (peixe de água marinha) em substituição parcial ao farelo de soja (Tabela 1).

Os resíduos de peixe de água doce, constituídos de cabeças, carcaças e vísceras, resultantes da filetagem de tilápia (Oreochromis niloticus), foram adquiridos em pesqueiros da região de Pirassununga, SP, enquanto os resíduos utilizados na silagem de resíduos de peixe de água marinha, compostos de cabeças e carcaça de peixe-sapo (Lophius gastrophisus), foram cedidos pela Gerbi Pescados, em Estiva Gerbi, SP.

As silagens foram produzidas em tambores de polietileno com capacidade para $100 \mathrm{~L}$, onde foram acondicionados $89,75 \%$ de resíduos do processamento de peixes triturados; 7,50\% de melaço de cana-de-açúcar; 2,50\% de iogurte natural; e 0,15\% de ácido sórbico. O material foi homogeneizado e os recipientes fechados hermeticamente por sete dias para produção de ácido lático, promovendo a redução do pH e inibição de microrganismos patogênicos. As composições percentual e bromatológica das dietas experimentais são apresentadas na Tabela 2.

Após período de adaptação às baias e às dietas (dez dias), deu-se início ao controle diário da quantidade de alimento fornecida e das sobras. O volumoso foi fornecido uma vez ao dia, às 8 h, e o concentrado, duas vezes ao dia, metade junto com o volumoso e o restante às $16 \mathrm{~h}$, com ajustes diários para permitir pelo menos $20 \%$ de sobras da dieta total.

Amostras de $10 \%$ das sobras de cada animal foram coletadas diariamente e armazenadas em freezer a $-18^{\circ} \mathrm{C}$ para formação, a cada semana, de uma amostra composta. As amostras compostas foram pré-secas em estufas de ventilação forçada a $55^{\circ} \mathrm{C}$, por 72 horas, e em seguida, foram trituradas em moinho de faca para determinação do teor de MS e da quantidade de MS consumida.

Os animais foram pesados ao início do experimento e a cada 14 dias para avaliação do ganho de peso e da conversão alimentar até atingirem $32 \mathrm{~kg}$ de peso corporal, quando foram realizadas as seguintes medidas biométricas (Searle et al., 1989; Yáñez et al., 2004): comprimento corporal (distância entre a articulação cérvicotorácica e a base da cauda na primeira articulação intercoccígea); altura do posterior (distância entre a tuberosidade sacra, na garupa, e a extremidade distal do membro posterior); altura do anterior (distância entre a região da cernelha e a extremidade distal do membro anterior); perímetro torácico (perímetro tomando-se como base o esterno e a cernelha). A condição corporal foi estimada de acordo com Russel et al. (1969) e Ribeiro et al. (2003), pela palpação da região dorsal da coluna vertebral, verificando-se a quantidade de gordura e músculo no ângulo formado pelos processos dorsais e transversos, atribuindo-se nota de 1 a $5 \pm 0$, 5 , em que 1 representou um animal com condição corporal inferior e 5 um animal excelente. Em seguida, calculou-se o índice de compacidade corporal, a partir da relação peso corporal/ comprimento corporal.

Após 30 dias do início do experimento de desempenho, foram sorteadas 12 fêmeas (quatro de cada dieta) para realização dos ensaios de digestibilidade e metabolismo. As fêmeas foram mantidas em gaiolas de metabolismo durante dez dias (cinco para adaptação e cinco para total de fezes e urina), efetuando-se o controle do consumo de alimento e água. A quantidade diária de fezes excretada foi

Tabela 1 - Composição bromatológica dos ingredientes das dietas experimentais (\% MS)

Table 1 - Chemical composition of the experimental feeds (\% DM)

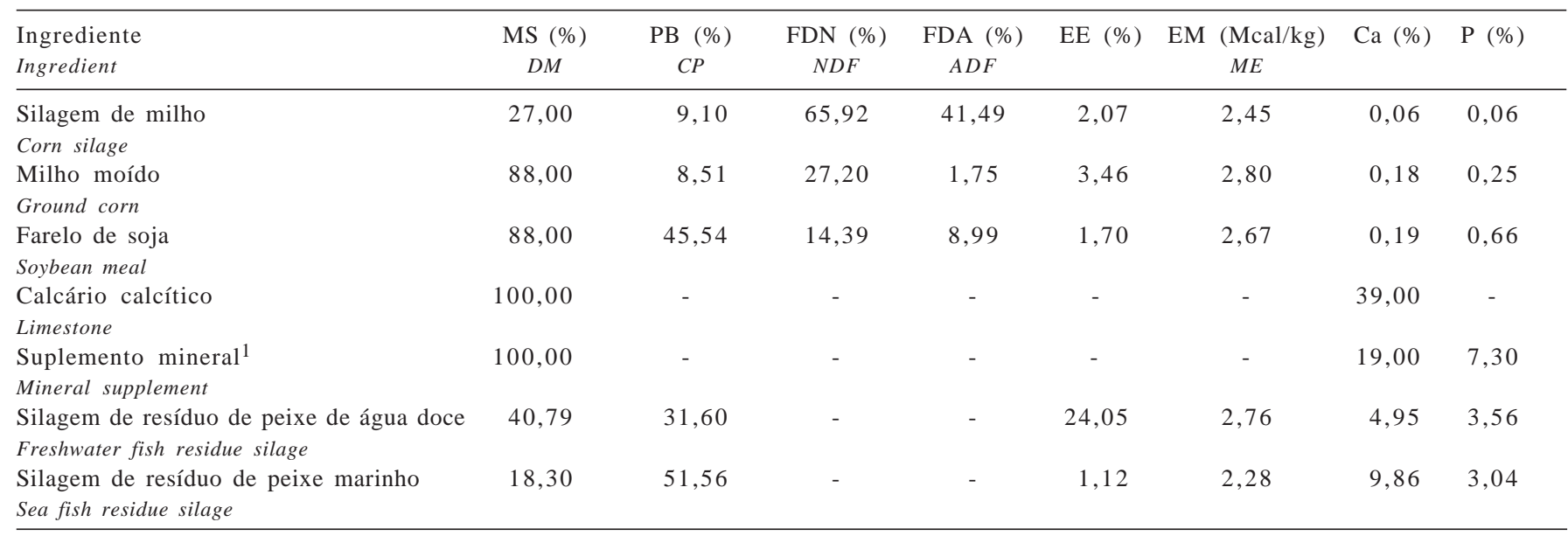

${ }^{1}$ Suplemento mineral (mineral supplement): Zn - 1.600 ppm; Cu - 300 ppm; Mn - 1.500 ppm; Fe - 1.100 ppm; Co - 10 ppm; I - 27 ppm; e Se - 22 ppm. 
Tabela 2 - Composições percentual e química das dietas experimentais (\% MS)

Table 2 - Ingredient and chemical compositions of the experimental diets (\% DM)

Ingrediente $(\%)$

Ingredient
Dieta $^{1}$

Diet

SRPAD SRPAM

Controle

Control

Milho moído (Ground corn)

Farelo de soja (Soybean meal)

Calcário calcítico (Limestone)

Suplemento mineral ${ }^{2}$ (Mineral supplement)

Silagem de resíduos de peixe de água doce (Freshwater fish residue silage)

Silagem de resíduos de peixe marinho (Sea fish residue silage)

Silagem de milho (Corn silage)

34,80

23,80

0,90

0,50

$-$

$-$

40,00

63,54
17,06
6,09
39,72
19,15
2,25
2,35

32,60

18,90

$-$

0,50

8,00

$-$

40,00

59,03

16,98

5,98

38,40

18,75

3,73

2,35
37,20

14,30

0,50

-

8,00

40,00
Composição química (Chemical composition)

(\%) $(D M)$

Cinzas (\%) (Ash)

FDA (\%) (ADF)

2,35

56,58

17,12

6,03

42,92

19,06

2,10

2,29

${ }^{1}$ Controle = dieta controle; SRPAD = dieta contendo silagem de resíduos de peixe de água doce; e SRPAM = dieta contendo silagem de resíduos de peixe marinho.

1 Control = control diet; SRPAD = freshwater fish residue silage diet; and SRPAM = sea fish residue silage diet.

2 Suplemento mineral (mineral supplement): Zn - 1.600 ppm; Cu - 300 ppm; Mn - 1.500 ppm; Fe - 1.100 ppm; Co - 10 ppm; I - 27 ppm; e Se - 22 ppm.

pesada em balança eletrônica. A urina foi coletada em baldes plásticos contendo $20 \mathrm{~mL}$ de $\mathrm{HCl}$ (1:1) para evitar a volatilização da amônia e mensurada em proveta com precisão de $10 \mathrm{~mL}$. Diariamente, foram retirados $10 \%$ do total de fezes e urina excretados e, ao final do período, foi obtida uma amostra composta de cada animal para posteriores análises laboratoriais.

Nas amostras de alimento fornecido, sobras e fezes, foram determinados os teores de MS, cinzas, nitrogênio total (N), PB, EE e FDN, conforme metodologia descrita por Silva \& Queiroz (2002). Os carboidratos totais (CT) foram obtidos pela equação: $100-(\% \mathrm{~PB}+\% \mathrm{EE}+\%$ cinzas $)$, enquanto os não-fibrosos (CNF), pela diferença entre CT e FDN (Sniffen et al., 1992). Os coeficientes de digestibilidade de MS, MO, PB, FDN, CT e CNF foram calculados pela diferença entre o ingerido e o excretado nas fezes, sendo utilizada a fórmula: digestibilidade aparente $(\%)=$ (ingerido (g) - excretado (g)/ingerido (g))*100.

Nas amostras de urina, foram determinados os teores de MS e N. O balanço aparente de nitrogênio (BN) foi calculado pelas seguintes fórmulas, e expresso em $\mathrm{g} / \mathrm{kg}^{0,75} / \mathrm{dia}$ :

$$
\begin{gathered}
\text { BN ou } \mathrm{N}_{\text {retido }}=\mathrm{N}_{\text {ingerido }}-\left(\mathrm{N}_{\text {fezes }}+\mathrm{N}_{\text {urina }}\right) ; \mathrm{N}_{\text {absorvido }}= \\
\mathrm{N}_{\text {ingerido }}-\mathrm{N}_{\text {fezes }} \text { e } \mathrm{N}_{\text {ingerido }}=\mathrm{N}_{\text {ofertado }}-\mathrm{N}_{\text {sobras }}
\end{gathered}
$$

Odelineamento experimental para o ensaio de desempenho foi o inteiramente casualizado, em modelo fatorial $3 \times 2$ (três dietas e dois sexos), com seis repetições. As variáveis estudadas foram submetidas à análise de variância (SAS, 1996) utilizando-se o seguinte modelo:

$$
\mathrm{Y}_{\mathrm{ijk}}=\mu+\mathrm{D}_{\mathrm{i}}+\mathrm{S}_{\mathrm{j}}+\mathrm{DS}_{\mathrm{ij}}+\mathrm{e}_{\mathrm{ijk}}
$$

em que $Y_{i j k}=$ valor observado da variável estudada no indivíduo k, do sexo j, alimentado com a dieta i; $\mu$ = média geral; $\mathrm{D}_{\mathrm{i}}=$ efeito da dieta $\mathrm{i}$, variando de $1 \mathrm{a} 3 ; \mathrm{S}_{\mathrm{j}}=$ efeito do sexo j, variando de 1 a $2 ; \mathrm{DS}_{\mathrm{ij}}=$ efeito da interação dieta $\times$ sexo; $e_{\mathrm{ijk}}=$ erro aleatório associado a cada observação.

Nos ensaios de digestibilidade e metabolismo, adotou-se o delineamento inteiramente casualizado, com três tratamentos e quatro repetições. Os dados foram submetidos a análise de variância (SAS, 1996), conforme o modelo matemático abaixo:

$$
\mathrm{Y}_{\mathrm{ij}}=\mu+\mathrm{D}_{\mathrm{i}}+\mathrm{e}_{\mathrm{ij}}
$$

em que $\mathrm{Y}_{\mathrm{ij}}=$ valor observado da variável estudada no indivíduo $\mathrm{j}$, alimentado com a dieta $\mathrm{i} ; \mu=$ média geral; $\mathrm{D}_{\mathrm{i}}=$ efeito da dieta $\mathrm{i} ; \mathrm{e}_{\mathrm{ij}}=$ erro aleatório associado a cada observação.

As médias foram comparadas pelo teste Tukey a 5\% de probabilidade.

\section{Resultados e Discussão}

Não houve efeito da interação dieta $\times$ sexo sobre o consumo de MS e o desempenho dos cordeiros (Tabela 3).

Os cordeiros terminados em confinamento alimentados com dietas contendo silagem de resíduos de peixes tiveram desempenho semelhante ao daqueles do grupo controle, 
Tabela 3 - Consumo de MS (CMS), ganho de peso diário (GPD) e conversão alimentar (CA) de cordeiros em confinamento alimentados com dietas contendo silagem de resíduos de peixe

Table 3 - DM intake (DMI), daily weight gain (DWG), feed conversion (FC) and feedlot time of lambs fed diets containing fish residue silages

\begin{tabular}{|c|c|c|c|c|c|c|}
\hline $\begin{array}{l}\text { Parâmetro } \\
\text { Item }\end{array}$ & $\begin{array}{l}\text { Consumo de } \\
\text { MS (g/dia) } \\
\text { DM intake } \\
\text { (g/day) }\end{array}$ & $\begin{array}{l}\text { Consumo de } \\
\text { MS (\%PV) } \\
\text { DM intake } \\
(\% \quad B W)\end{array}$ & $\begin{array}{c}\text { Consumo de } \\
\left.\text { MS (g/kg } / \mathrm{kg}^{0,75} / \mathrm{dia}\right) \\
D M \text { intake } \\
\left(\mathrm{g} / \mathrm{kg}^{0.75} / \text { day }\right)\end{array}$ & $\begin{array}{c}\text { Ganho de peso } \\
\text { diário (g/dia) } \\
\text { Daily weight gain } \\
\text { (g/day) }\end{array}$ & $\begin{array}{c}\text { Conversão alimentar } \\
\text { (kg MS/kg GPD) } \\
\text { Feed conversion } \\
(\mathrm{kg} D M / \mathrm{kg} D W G)\end{array}$ & $\begin{array}{c}\text { Duração do } \\
\text { confinamento (dias) } \\
\text { Feedlot time } \\
\text { (days) }\end{array}$ \\
\hline
\end{tabular}

$\operatorname{Dieta}^{1}$ (Diet)

\begin{tabular}{|c|c|c|c|c|c|c|}
\hline Controle (Control) & 899,74 & 3,56 & 79,81 & 239,38 & $3,81^{\mathrm{a}}$ & 63,62 \\
\hline SRPAD & 883,87 & 3,52 & 78,75 & 256,06 & $3,47^{\mathrm{a}}$ & 62,47 \\
\hline SRPAM & 891,87 & 3,55 & 79,59 & 225,33 & $4,04^{\mathrm{b}}$ & 64,03 \\
\hline \multicolumn{7}{|l|}{ Sexo (Gender) } \\
\hline Macho (Male) & 880,68 & 3,49 & 78,47 & 245,96 & 3,72 & 65,92 \\
\hline Fêmea (Female) & 902,41 & 3,58 & 80,29 & 237,21 & 3,83 & 60,83 \\
\hline $\begin{array}{l}\text { Fonte de variação } \\
\text { Source of variation }\end{array}$ & \multicolumn{6}{|c|}{$\begin{array}{l}\text { Valor de } \mathrm{F} \\
\quad \text { F value }\end{array}$} \\
\hline Dieta (Diet) & 0,13 & 0,05 & 0,08 & 2,16 & $3,44 *$ & 0,04 \\
\hline Sexo (Gender) & 0,65 & 0,65 & 0,60 & 0,37 & 0,43 & 0,21 \\
\hline Dieta x Sexo (Diet x Gender) & 0,01 & 0,15 & 0,12 & 0,33 & 0,49 & 0,12 \\
\hline CV (\%) & 8,21 & 8,11 & 8,08 & 16,06 & 14,07 & 20,35 \\
\hline
\end{tabular}

Médias seguidas de letras diferentes na coluna diferem pelo teste Tukey.

* Significativo $(P<0,05)$.

${ }^{1}$ Controle = dieta controle; SRPAD = dieta contendo silagem de resíduos de peixe de água doce; e SRPAM = dieta contendo silagem de resíduos de peixe marinho.

Means followed by different letters in the same column are different by Tukey test

* Significant $(P<0.05)$.

1 Control = control diet; SRPAD = freshwater fish residue silage diet and SRPAM = sea fish residue silage diet .

pois o tempo de confinamento não diferiu entre as dietas, com média de 63,37 dias.

Fontes protéicas alternativas em substituição ao farelo de soja são muito estudadas no intuito de reduzir os custos com alimentação na terminação de cordeiros em confinamento, porém, trabalhos utilizando silagem de peixe como fonte protéica são escassos. Bona Filho et al. (1994), avaliando a inclusão de 0; 3,3; 6,6 e 9,9\% de farinha de peixe na dieta de cordeiros em confinamento, verificaram melhores ganhos de peso (329,05 g/dia) nos animais alimentados com dietas contendo $6,6 \%$ de farinha de peixe, enquanto aqueles alimentados com a dieta sem esse ingrediente tiveram ganho de 269,52 g/dia, superior ao dos cordeiros deste experimento (240,26 g/dia). No entanto, esses autores não verificaram diferenças na conversão alimentar (4,94) e no consumo de MS (4,34\% do peso corporal). O ganho diário dos cordeiros deste experimento foi semelhante ao de 239,00 g/dia obtido por Marques et al. (2003) em cordeiros 7/8 IIe de France 1/8 Ideal alimentados com dietas contendo 2,66 Mcal de EM/kg de MS e $16 \%$ de PB.

$\mathrm{O}$ consumo médio diário de MS não diferiu $(\mathrm{P}>0,05)$ entre dietas e sexo, com média de $892 \mathrm{~g} /$ dia. Samuels et al. (1991) verificaram que ovinos alimentados com dieta controle apresentaram consumo de MS superior ao daqueles alimentados com dieta contendo silagens de resíduos de caranguejoedepeixe(1.217,708e1.194g/dia, respectivamente).
Dabiri \& Thonney (2004) não notaram diferença no consumo de MS (1,079 vs 1,099 g/dia), no ganho de peso diário (291 vs 292 g/dia) e na eficiência alimentar (269 vs 266 g/kg MS) de cordeiros em crescimento alimentados com dietas suplementadas com farelo de soja ou farelo de soja + farinha de peixe.

A conversão alimentar dos cordeiros alimentados com a dieta contendo silagem de resíduo de peixe de água marinha $(4,04)$ foi pior que a obtida com a dieta controle $(3,81)$ e aquela contendo silagem de resíduos de peixe de água doce $(3,47)$.

Não houve influência $(\mathrm{P}>0,05)$ das dietas sobre as medidas biométicas dos cordeiros (Tabela 4), entretanto, os cordeiros apresentaram maiores comprimento corporal $(60,09 \mathrm{~cm})$ e altura do anterior $(56,11 \mathrm{~cm})$ em relação às cordeiras, cujas medidas foram de 58,03 e 54,75 cm, respectivamente.

A compacidade corporal é um índice que estima objetivamente a conformação nos animais vivos a partir dos valores de peso corporal e comprimento corporal, considerados de fácil determinação, indicando que, quanto maior a relação $\mathrm{kg} / \mathrm{cm}$, maior a proporção de músculos e gordura no animal (Yáñez et al., 2004). A compacidade corporal $(0,55)$ foi semelhante entre as dietas, o que confirma a semelhança no ganho de peso e na condição corporal dos cordeiros alimentados com as diferentes dietas. 
Tabela 4 - Medidas morfológicas in vivo de cordeiros em confinamento alimentados com dietas contendo silagens de resíduos de peixes Table 4 - In vivo morphological measurements of feedlot lambs fed diets containing fish residue silages

\begin{tabular}{|c|c|c|c|c|c|c|c|}
\hline $\begin{array}{l}\text { Parâmetro** } \\
\text { Item }\end{array}$ & $\begin{array}{c}\mathrm{PV}(\mathrm{kg}) \\
B W\end{array}$ & $\begin{array}{l}\text { CCO } \\
B C O\end{array}$ & $\begin{array}{c}\text { COC }(\mathrm{cm}) \\
B L E\end{array}$ & $\begin{array}{c}\mathrm{AA}(\mathrm{cm}) \\
A H\end{array}$ & $\begin{array}{c}\mathrm{AP}(\mathrm{cm}) \\
P H\end{array}$ & $\begin{array}{c}\mathrm{PT}(\mathrm{cm}) \\
T C\end{array}$ & $\begin{array}{c}\text { CCOR }(\mathrm{kg} / \mathrm{cm}) \\
B C\end{array}$ \\
\hline \multicolumn{8}{|l|}{$\operatorname{Dieta}^{1}$ (Diet) } \\
\hline $\begin{array}{l}\text { Controle (Control) } \\
\text { SRPAD } \\
\text { SRPAM }\end{array}$ & $\begin{array}{l}32,66 \\
32,69 \\
32,19\end{array}$ & $\begin{array}{l}3,70 \\
3,81 \\
3,69\end{array}$ & $\begin{array}{l}59,42 \\
58,31 \\
59,46\end{array}$ & $\begin{array}{l}56,06 \\
55,69 \\
55,29\end{array}$ & $\begin{array}{l}56,29 \\
55,87 \\
55,15\end{array}$ & $\begin{array}{l}75,22 \\
75,31 \\
75,46\end{array}$ & $\begin{array}{l}0,55 \\
0,56 \\
0,54\end{array}$ \\
\hline \multicolumn{8}{|l|}{ Sexo (Sex) } \\
\hline $\begin{array}{l}\text { Macho (Male) } \\
\text { Fêmea (Female) }\end{array}$ & $\begin{array}{l}32,87^{\mathrm{a}} \\
32,16^{\mathrm{b}}\end{array}$ & $\begin{array}{l}3,79 \\
3,67\end{array}$ & $\begin{array}{l}60,09^{\mathrm{a}} \\
58,03^{\mathrm{b}}\end{array}$ & $\begin{array}{l}56,11^{\mathrm{a}} \\
54,75^{\mathrm{b}}\end{array}$ & $\begin{array}{l}56,43 \\
55,11\end{array}$ & $\begin{array}{l}74,43 \\
76,23\end{array}$ & $\begin{array}{l}0,55 \\
0,55\end{array}$ \\
\hline $\begin{array}{l}\text { Fonte de variação } \\
\text { Source of variation }\end{array}$ & & & & $\begin{array}{c}\text { Valor de } \mathrm{F} \\
F \text { value }\end{array}$ & & & \\
\hline $\begin{array}{l}\text { Dieta (Diet) } \\
\text { Sexo (Sex) } \\
\text { Dieta x sexo (Diet } x \text { sex) } \\
\text { CV }(\%)\end{array}$ & $\begin{array}{l}1,07 \\
5,12 * \\
0,85 \\
2,76\end{array}$ & $\begin{array}{l}0,26 \\
0,55 \\
3,22 \\
1,85\end{array}$ & $\begin{array}{l}0,76 \\
5,70^{*} \\
4,48 \\
4,68\end{array}$ & $\begin{array}{l}0,31 \\
5,48^{*} \\
2,64 \\
4,24\end{array}$ & $\begin{array}{l}0,70 \\
2,76 \\
2,33 \\
4,07\end{array}$ & $\begin{array}{l}0,02 \\
4,05 \\
1,37 \\
3,25\end{array}$ & $\begin{array}{l}1,26 \\
0,66 \\
1,69 \\
4,99\end{array}$ \\
\hline
\end{tabular}

Médias seguidas de letras diferentes na coluna diferem pelo teste Tukey.

* Significativo $(P<0,05)$.

** $\mathrm{PV}=$ peso vivo; $\mathrm{CCO}=$ condição corporal; $\mathrm{COC}=$ comprimento corporal; $\mathrm{AA}=$ altura do anterior; $\mathrm{AP}=$ altura do posterior; $\mathrm{PT}=$ perímetro torácico e CCOR = compacidade corporal.

1 Controle = dieta controle; SRPAD = dieta contendo silagem de resíduos de peixe de água doce e SRPAM = dieta contendo silagem de resíduos de peixe marinho.

Means followed by different letters in column are different by Tukey test.

* Significant $(P<0.05)$.

** $B W=$ body weight $B C O=$ body condition; $B L E=$ body length $; A H=$ anterior height $P H=$ posterior height $; C=$ thoracic circumference and $B C=$ body compactness

1 Control = control diet; SRPAD = freshwater fish residue silage diet and SRPAM = sea fish residue silage diet.

Os consumos médios diários e os coeficientes de digestibilidade aparente das diferentes frações da dieta podem ser visualizados na Tabela 5. A inclusão de silagem de peixe de água doce elevou o teor de EE, assim como sua ingestão e a digestibilidade da dieta. Cordeiras alimentadas com dieta contendo silagem de resíduo de peixe de água doce apresentaram maior ingestão de $\operatorname{EE~}(3,20 \mathrm{~g} /$ $\left.\mathrm{kg}^{0,75} / \mathrm{dia}\right)$, o que pode ser explicado pelo maior teor de EE desta dieta $(3,73 \%)$ em comparação aos teores da dieta controle $(2,25 \%)$ e daquela contendo silagem de resíduo de peixe marinho (2,10\%). Esse fato também explica o maior coeficiente de digestibilidade do EE (90,39\%) desta dieta. O coeficiente de digestibilidade da FDN foi maior $(\mathrm{P}<0,05)$ nas dietas contendo silagem de resíduos de peixes e indica que os teores de EE das rações não afetaram a digestibilidade da fibra.

Shqueir et al. (1984) notaram aumento dos coeficientes de digestibilidade do EE (51,4; 55,6; 57,8 e 58,9\%) e da FDA (48,3; 51,8; 52,6 e 52,7\%) quando incluíram 0, 5, 10 e 15\% de silagem de peixe na dieta de ovinos. Esses autores verificaram também aumento na digestibilidade da FDN da dieta com a inclusão de silagens de peixe e atribuíram o fato ao aumento da eficiência ruminal, provavelmente em virtude da maior disponilidade de aminoácidos para biossíntese ruminal. Hall (1984) encontrou aumento da digestibilidade do EE da dieta contendo silagem de resíduo de peixe em comparação à dieta contendo silagem de resíduo de caranguejo e à dieta controle (92,7; 82,1 e 71,4\%, respectivamente). Esses autores, no entanto, observaram redução da digestibilidade da FDN de $71,8 \%$ (dieta controle) para 56,5 e 56\% em dietas contendo silagens de resíduos de peixe e caranguejo, respectivamente. Sales et al. (2002), trabalhando com dietas contendo $60 \%$ de FDN, relataram não haver diferença na digestibilidade da fibra em dietas com diferentes níveis de silagem de resíduo de peixe e encontraram valor de $63 \%$. Reddy et al. (2003) verificaram que a adição de $5 \%$ de lipídios na dieta de cordeiros elevou a digestibilidade do EE de 58 para $80 \%$ e não ocasionou redução na digestibilidade da FDN, que foi de 51 para $50 \%$.

Os coeficientes de digestibilidade da MS, MO e PB foram 76,09; 77,31 e 70,36\%, respectivamente. Shqueir et al. (1984) observaram valores superiores ao encontrado neste trabalho e aumento na digestibilidade de PB da dieta de ovinos, com valores de 72; 78,6; 78,7 e 80\% para dietas com 0, 5, 10 e 15\% de silagem de peixe. Sales et al. (2002) verificaram redução na digestibilidade da PB de 78 para $73 \%$ conforme aumentaram o nível de silagem de resíduo de pescado na dieta dos animais. No entanto, Geron (2003), ao avaliar dieta com $8 \%$ de silagem fermentada de resíduo de peixe de água doce (tilápia) na alimentação de novilhos holandeses, encontrou digestibilidade da MS, MO e PB de 59,$1 ; 62,9$ e 59,1\%, respectivamente.

O consumo de água pelas cordeiras alimentadas com a dieta controle foi de $2.709 \mathrm{~mL} /$ dia, superior $(\mathrm{P}>0,05)$ ao 
daquelas alimentadas com a dieta com silagem de resíduo de peixe de água doce. Ambos os valores diferiram $(\mathrm{P}<0,05)$ da ingestão de $1.728,5 \mathrm{~mL} /$ dia de água pelas cordeiras alimentadas com a dieta com silagem de resíduo de peixe marinho, provavelmente por estar relacionada ao maior teor de umidade $(43,42 \%)$ desta dieta, que reduziu a ingestão da água de bebida.

Na Tabela 6 encontra-se o consumo de água pelas cordeiras em confinamento.
Quando expresso em porcentagem do peso corporal e em g/kg0,75/dia, o consumo de água não diferiu entre as cordeiras. Swanson et al. (2000), avaliando a suplementação de diferentes níveis de proteína não-degradada no rúmen em ovinos adultos, observaram consumo de água de $2028 \mathrm{~mL} /$ dia.

Em todas as dietas, o balanço de $\mathrm{N}$ obtido foi positivo (Tabela 7). Não houve efeito $(\mathrm{P}>0,05)$ das dietas sobre as quantidades de $\mathrm{N}$ ingerido, excretado nas fezes e na urina, retido (balanço de $\mathrm{N}$ ) e absorvido, o que era esperado,

Tabela 5 - Consumo e coeficientes de digestibilidade aparente de nutrientes da dieta em cordeiros alimentados com dietas contendo silagens de resíduos de peixes

Table 5 - Intake and apparent digestibility coefficients $(D C)$ of nutrients in feedlot lambs fed diets containing fish residue silages

\begin{tabular}{|c|c|c|c|c|c|}
\hline \multirow[t]{2}{*}{$\begin{array}{l}\text { Consumo } \\
\text { Intake }\end{array}$} & \multicolumn{3}{|c|}{$\begin{array}{l}\text { Dieta }^{1} \\
\text { Diet }^{1}\end{array}$} & \multirow[t]{2}{*}{ CV (\%) } & \multirow[t]{2}{*}{$\begin{array}{c}\text { Valor de } \mathrm{F} \\
\quad \text { F value }\end{array}$} \\
\hline & $\begin{array}{l}\text { Controle } \\
\text { Control }\end{array}$ & SRPAD & SRPAM & & \\
\hline MS (g/kg0,75/dia) (DM, g/kg $0.75 /$ day $)$ & 78,24 & 84,06 & 81,72 & 10,73 & 0,40 \\
\hline MO (g/kg0,75/dia) (OM, g/kg $0.75 /$ day $)$ & 73,37 & 79,25 & 76,78 & 10,69 & 0,47 \\
\hline PB (g/kg $\left./ \mathrm{kg}^{0,75} / \mathrm{dia}\right)\left(C P, \mathrm{~g} / \mathrm{kg}^{0.75} /\right.$ day $)$ & 13,34 & 14,16 & 14,31 & 11,29 & 0,39 \\
\hline CT $\left(\mathrm{g} / \mathrm{kg}^{0,75} / \mathrm{dia}\right)\left(T C, \mathrm{~g} / \mathrm{kg}^{0.75} /\right.$ day $)$ & 58,24 & 61,88 & 60,72 & 10,40 & 0,31 \\
\hline CNF (g/kg0,75/dia) (NFC, g/kg $0.75 /$ day $)$ & 29,50 & 32,34 & 27,99 & 11,28 & 0,28 \\
\hline \multicolumn{6}{|l|}{$\begin{array}{l}\text { Coeficiente de digestibilidade } \\
\text { Digestible coefficient }\end{array}$} \\
\hline MS (\%) (DM) & 74,95 & 77,72 & 75,62 & 2,48 & 3,34 \\
\hline CT (\%) (TC) & 76,91 & 80,31 & 78,51 & 2,79 & 3,48 \\
\hline CNF (\%) (NFC) & 93,84 & 94,28 & 92,82 & 2,17 & 0,49 \\
\hline
\end{tabular}

Médias seguidas de letras diferentes na coluna diferem pelo teste Tukey.

* Significativo $(P<0,05)$.

1 Controle = dieta controle; SRPAD = dieta contendo silagem de resíduos de peixe de água doce e SRPAM = dieta contendo silagem de resíduos de peixe marinho.

Means followed by different letters in column are different by Tukey test.

* Significant $(P<0.05)$.

1 Control = control diet; SRPAD = freshwater fish residue silage diet and SRPAM = sea fish residue silage diet.

Tabela 6 - Consumo de água por cordeiros alimentados com dietas contendo silagens de resíduos de peixes Table 6 - Water intake of feedlot lambs fed diets containing fish residue silages

\begin{tabular}{|c|c|c|c|c|c|}
\hline \multirow[t]{2}{*}{$\begin{array}{l}\text { Consumo de água } \\
\text { Water intake }\end{array}$} & \multicolumn{3}{|c|}{$\begin{array}{l}\text { Dieta }^{1} \\
\text { Diet }^{1}\end{array}$} & \multirow[t]{2}{*}{ CV (\%) } & \multirow[t]{2}{*}{$\begin{array}{l}\text { Valor de } \mathrm{F} \\
\text { F value }\end{array}$} \\
\hline & $\begin{array}{c}\text { Controle } \\
\text { Control }\end{array}$ & SRPAD & SRPAM & & \\
\hline $\mathrm{mL} /$ dia $(\mathrm{mL} /$ day $)$ & $2.709,00^{\mathrm{a}}$ & $2.138,00^{\mathrm{a}}$ & $1.728,50^{\mathrm{b}}$ & 25,24 & $6,13^{*}$ \\
\hline$\%$ peso corporal (\% body weight) & 11,13 & 8,30 & 6,99 & 31,42 & 3,34 \\
\hline $\mathrm{g} / \mathrm{kg}^{0,75} / \mathrm{dia}\left(\mathrm{g} / \mathrm{kg}^{0.75} /\right.$ day $)$ & 246,89 & 186,70 & 155,84 & 29,39 & 3,95 \\
\hline
\end{tabular}


Tabela 7 - Balanço aparente de $\mathrm{N}\left(\mathrm{g} / \mathrm{kg}^{0,75} / \mathrm{dia}\right)$ da dieta de cordeiros terminados em confinamento com dietas contendo silagens de resíduos de peixes

Table 7 - Apparent $\mathrm{N}$ balance $\left(\mathrm{g} / \mathrm{kg}^{0.75} /\right.$ day) in feedlot lambs fed diets containing fish residue silages

\begin{tabular}{|c|c|c|c|c|c|}
\hline \multirow[t]{2}{*}{ Item } & \multicolumn{3}{|c|}{$\begin{array}{c}\text { Dieta }^{1} \\
\text { Diet }^{1}\end{array}$} & \multirow[t]{2}{*}{ CV (\%) } & \multirow[t]{2}{*}{$\begin{array}{c}\text { Valor de } \mathrm{F} \\
\text { F value }\end{array}$} \\
\hline & $\begin{array}{c}\text { Controle } \\
\text { Control }\end{array}$ & SRPAD & SRPAM & & \\
\hline Nitrogênio ingerido (Nitrogen intake) & 2,59 & 2,54 & 2,46 & 11,43 & 0,18 \\
\hline Nitrogênio fezes (Fecal nitrogen) & 0,59 & 0,59 & 0,61 & 15,20 & 0,06 \\
\hline Nitrogênio urina (Urinariy nitrogen) & 0,84 & 0,79 & 0,83 & 12,92 & 3,17 \\
\hline $\mathrm{N}$ retido/ $\mathrm{N}$ ingerido (Retained $\mathrm{N} / \mathrm{N}$ intake) & 0,44 & 0,45 & 0,41 & 13,55 & 0,45 \\
\hline $\mathrm{N}$ retido/N absorvido (Retained N/absorbed $N$ ) & 0,58 & 0,59 & 0,55 & 11,12 & 3,36 \\
\hline
\end{tabular}

Médias não diferiram $(\mathrm{P}>0,05)$ pelo teste Tukey.

${ }^{1}$ Controle = dieta controle; SRPAD = dieta contendo silagem de resíduos de peixe de água doce e SRPAM = dieta contendo silagem de resíduos de peixe marinho.

Means are not different $(P>0.05)$ by Tukey test.

${ }^{1}$ Control = control diet; SRPAD = freshwater fish residue silage diet and SRPAM = sea fish residue silage diet .

pois as dietas fornecidas eram isoprotéicas. Segundo Owens \& Zinn (1988), a retenção de nitrogênio (balanço de N) serve como estimativa da deposição de proteína para fatores produtivos, como lã, leite e carne. Desse modo, a similaridade no ganho de peso dos cordeiros (Tabela 3) pode ser explicada, em parte, pela similaridade na retenção de nitrogênio (Tabela 7).

Shqueir et al. (1984), estudando o metabolismo do nitrogênio em ovinos alimentados com dietas contendo silagem de peixe, encontraram valores de retenção de nitrogênio de 0,$5 ; 0,5 ; 0,6$ e $0,7 \mathrm{~g} / \mathrm{kg}^{0,75} /$ dia para os níveis de 0 , 5,10 e $15 \%$ de silagem de peixe, respectivamente. Samuels et al. (1991) observaram maior retenção de nitrogênio em animais consumindo dieta contendo silagem de resíduo de caranguejo (4,4 g/dia) em comparação aos animais alimentados com dieta contendo silagem de resíduo de peixe (2,4 g/dia), o que pode ser explicado pelo maior teor de PB da dieta com silagem de resíduo de caranguejo (31,50\%) em relação à dieta com silagem de resíduo de peixe (17,30\%).

\section{Conclusões}

Considerando o desempenho, a digestibilidade dos nutrientes e o balanço de nitrogênio obtidos neste estudo, a substituição parcial do farelo de soja por silagem de resíduos de peixes mostrou-se como boa alternativa alimentar, o que valida a utilização deste ingrediente como fonte protéica alternativa na alimentação de cordeiros.

\section{Literatura Citada}

AGRICULTURAL AND FOOD RESEARCH COUNCIL - AFRC. Energy and protein requirements of ruminants. Washington: CAB International, 1995. 159p.
BONA FILHO, A.; OTTO, C.; LEME, M.C. et al. Ganho de peso e características de carcaça de cordeiros confinados e suplementados com diferentes níveis de farinha de peixe em substituição ao farelo de soja. Revista do Setor de Agrárias, v.13, n.1, p.183-191, 1994.

DABIRI, N.; THONNEY, M.L. Source and level of supplemental protein for growing lambs. Journal of Animal Science, v.82, n. 11, p. 3237-3244, 2004.

GERON, L.J.V. Produção e utilização da silagem do resíduo da filetagem de tilápia na alimentação de ruminantes. Maringá: Universidade Estadual de Maringá, 2003. 70p. Dissertação (Mestrado em Zootecnia) - Universidade Estadual de Maringá, 2003.

HALL, G.M. Silage from tropical fish. Nothingham: University of Nothingham, 1984. 230p. Thesis (Ph.D.) - University of Nothingham, 1984.

HARRIS, L.E. Compilação de dados analíticos e biológicos para o preparo de tabelas de composição de alimentos para uso nos trópicos da América Latina. Florida: Centro de Agricultura Tropical, 1970. 5301p.

ÍTAVO, L.C.V.; VALADARES FILHO, S.C.; SILVA, F.F. et al. Consumo e digestibilidades aparentes totais e parciais de nutrientes em novilhos alimentados com dietas contendo vários níveis de concentrado. Revista Brasileira de Zootecnia, v.31, n.3, p.1543-1552, 2002.

MAIA JR., W.M.; NARAIN, N.; BORA, P.S. et al. Aminoacid composition of tilapia (Oreochromis niloticus) residue silage. In: INTERNATIONAL SYMPOSIUM ON TILAPIA AQUACUlture, 5., 2000, Rio de Janeiro. Anais... Rio de Janeiro: Panorama da Aqüicultura Magazine, 2000. p. 446-450.

MARQUES, C.A.T.; SILVA SOBRINHO, A.G.; GONZAGA NETO, S. et al. Desempenho e digestibilidade de dietas para cordeiros terminados em confinamento. In: REUNIÃO ANUAL DA SOCIEDADE BRASILEIRA DE ZOOTECNIA, 40., 2003, Santa Maria. Anais... Santa Maria: Sociedade Brasileira de Zootecnia, 2003. (CD-ROM).

OETTERER, M. Produção de silagem a partir da biomassa residual do pescado. Alimentos e Nutrição, v.5, p.119-134, 1993.

OWENS, F.N; ZINN, R. Protein metabolism of ruminant animals. In: CHURCH, D.C. (Ed.) The ruminant animal. Englewood Cliffs: Waveland Press, 1988. p.227-249.

REDDY, R.Y.; KRISHNA, N.; RAO, R.E. et al. Influence of dietary protected lipids on intake and digestibility of straw based diets in Deccani sheep. Animal Feed Science and Technology, v.106, n.1, p.29-38, 2003. 
RIBEIRO, L.A.O.; FONTANA, C.S.; WALD, V.B. et al. Relação entre a condição corporal e a idade das ovelhas no encarneiramento com a prenhez. Ciência Rural, v.33, n.2, p.357-361, 2003.

RUSSEL, A.J.F.; DONEY, J.M.; GUNN, R.G. Subjctive assessment of body fat in live sheep. Journal of Agricultural Science, v.72, n.3, p.451-454, 1969.

SALES, R.O.; RODRIGUES, A.C.O.; AZEVEDO, A.R. et al. Efeito da inclusão de silagem biológica de resíduos de pescado sobre a digestibilidade de dietas para ovinos. In: REUNIÃO ANUAL DA SOCIEDADE BRASILEIRA DE ZOOTECNIA, 39., 2002 Recife. Anais... Recife: Sociedade Brasileira de Zootecnia, 2002. (CD-ROM).

SAMUELS, W.A.; FONTENOT, J.P.; ALLEN, V.G. et al. Seafood processing wastes ensiled with straw: utilization and intake by sheep. Journal of Animal Science, v.69, n.12, p.4983-4992, 1991.

STATISTICAL ANALYSIS SYSTEMS - SAS. User's guide. Cary: 1996. (CD-ROM).

SEARLE, T.W.; GRAHAM, McC.; DONNELLY, J.B. Change of skeletal dimensions during growth in sheep: the effect of nutrition. Journal of Agricultural Science, v.112, n.3, p.321327, 1989.

SILVA, D.J.; QUEIROZ, A.C. Análise de alimentos: métodos químicos e biológicos. 3.ed. Viçosa, MG: Editora UFV, 2002, $235 p$.

SHQUEIR, A.A.; CHURCH, D.C.; KELLEMS, R.O. Evaluation of liquefied fish in digestibility and feedlot performance studies with sheep. Canadian Journal Animal Science, v.64, n.4, p.889-898, 1984.
SNIFFEN, C.J.; CONNOR, J.D.; Van SOEST, P.J. A net carbohydrate and protein system for evalution cattle diets. II. Carboydrate and protein availability. Journal of Animal Science, v.70, n.11, p.3562-3577, 1992.

SWANSON, K.C.; CATON, J.S.; REDMER, D.A. et al. Influence of undegraded intake protein on intake, digestion, serum hormones and metabolites, and nitrogen balance in sheep. Small Ruminant Research, v.35, n.3, p.225-233, 2000.

URBANIAK, M. Effects of blood meal, fish meal, soybean meal or casein on growth and body composition in lambs. Small Ruminant Research, v.18, n.3, p.213-217, 1995.

VIDOTTI, R.M.; CARNEIRO, D.J.; VIEGAS, E.M.M. Growth rate of pacu (Piaractus mesopotamicus) fingerlings fed diets containing co-dried fish silage as replacement of fish meal. Journal of Applied Aquaculture, v.12, n.4, p.77-88, 2002.

WINDSOR, M.; BARLOW, S. Introducción a los subproductos de pesqueria. Zaragoza: Acribia, 1984. 240p.

YÁÑEZ, E.A.; RESENDE, K.T.; FERREIRA, A.C.D. et al. Utilização de medidas biométricas para predizer características da carcaça de cabritos Saanen. Revista Brasileira de Zootecnia, v.33, n.6, p.1564-1572, 2004. 